CP, 2020, Vol.9 - No18, pp. 43/58 ISSN 2014-6752. Girona (Catalunya). Universitat de Girona. PÉREZ-GÓMEZ, M.A.; ECHAZARRETA SOLER, C.; AUDEBERT, M.; SANCHEZ MIRET, C.: El ciberacoso como elemento articulador de las nuevas violencias digitales: métodos y contextos. Recibido: 06/07/2020- Aceptado: 18/07/2020

\title{
El ciberacoso como elemento articulador de las nuevas violencias digitales: métodos y contextos
}

\section{Cyberbullying as an articulating element of the new digital violence: methods and contexts}

\author{
Autores: \\ Miguel Angel Pérez-Gómez \\ Universidad de Sevilla \\ Carmen Echazarreta Soler \\ Universitat de Girona \\ Meritxell Audebert \\ Universitat de Girona \\ Cristina Sánchez Miret \\ Universitat de Girona
}

\section{Resumen}

Las redes sociales han supuesto una revolución social y cultural generando dinámicas sociales muy positivas. Pero también ha supuesto una nueva variante de delitos relacionados con la integridad física, psicológica e intelectual de los individuos. A través de este artículo se pretende poner de manifiesto lo que suponen esta serie de conductas delictivas que tienen como base el ciberacoso. La palabra ciberacoso se utiliza de manera general para definir una serie de prácticas y más especificas que las propias de este término. Esta investigación busca conceptualizar y distinguir las diversas formas de abuso y agresión como es el ciberbullying, el ciberacoso sexual, el grooming o el ciberstalking y otras, que se definirán a lo largo de este texto como un punto de partida para poder identificarlas e intentar atajarlas. La metodología utilizada es exploratoria-descriptiva.

Palabras clave: ciberacoso, acoso sexual, grooming online, redes sociales, sextorsión, TIC.

\section{Abstract}

Social networks have brought a social and cultural revolution, generating very positive social dynamics. But it has also involved a new variant of crimes related to the physical, psychological and intelectual integrity of individuals. Through this article, it is intended to highlight what this series of criminal behaviors based on cyberbullying. The word cyberbullying is used in a general way to define a series of practices and more specific tan those of this term. This research seeks to conceptualize and distinguish the various forms of abuse and aggression such as cyberbullying, sexual cyberbullying, grooming or cyberstalking and others, which will be defined throughout this text as a starting point to identify and try to tackle them. The methodology used is exploratory-descriptive.

Keywords: Cyberbullying, ICT, online grooming, sextortion, sexual harassment, Social networks. 


\section{Introducción}

Hay una tendencia a demonizar las redes sociales por su función mediadora entre los individuos que acosan y sus víctimas, pues Internet, sin duda, ha amplificado las conductas delictivas que acaban persiguiendo, acechando y acosando de forma compulsiva a su víctima, sin que las negativas de esta cambien su obsesión. La presente investigación pretende aportar una conceptualización del acoso a través de plataformas digitales que ayude a eliminar esta lacra social por parte de todas las Instituciones implicadas en las diversas situaciones.

El ciberacoso es una conducta abyecta que se manifiesta de formas distintas según sea el entorno de la víctima y el objetivo que se persigue. Diversos autores han tratado de aportar una definición que acotara todas sus manifestaciones: "Aquella forma de comportamiento agresivo no deseado, realizado por otro individuo o grupo, con el/los cual/cuales la relación no es amistosa, que supone la percepción de un desequilibro de poder de forma repetitiva, o con altas probabilidades de repetirse" (Gladden et al., 2014). Cada vez son más los casos de acoso que salen a luz, en la mayoría de los cuales las víctimas han sido el blanco de una serie de conductas y comportamientos vejatorios llevados a cabo por otra persona conocida como agresor $\mathrm{o}$ acosador.

Este artículo teórico de investigación parte de la necesidad de conceptualizar y distinguir las diversas formas de abuso y agresión como es el ciberbullying, el ciberacoso sexual, el grooming o el ciberstalking y otras, que desarrollaremos debidamente a continuación. El acoso puede tomar muchas formas y darse en una gran variedad de contextos por ello durante los últimos años son muchos los estudios realizados por parte de educadores, psicólogos y criminólogos, entre otros, sobre el acoso y sus variantes digitales. Se ha mostrado como un campo de estudio en el que podemos observar dos grandes vertientes. Una de carácter multidisciplinar en la que podemos incluir algunas de las disciplinas anteriormente citadas y que pretender acotar cada una de estas acciones a través de diferentes frentes. Desde la psicología autores como Dan Olweus o Maite Garaigordobil que investigan la intersección de estas prácticas con las TIC, desde el ámbito de la psicología aplicada a la pedagogía Marilyn A. Campbell, autores como Tokunaga que investigan la interacción con los ordenadores en el ámbito del comportamiento humano; pero también desde los estudios en criminología como los estudios realizados por Hinduja y Patchin. Otro lado también se han utilizado datos de instituciones como el INTECO (Instituto Nacional de Tecnologías de la Comunicación), Europol, y Ong's como Save the Children que trabajan sobre el terreno ayudando a la infancia.

La segunda seria la legal, con un autor como Victoriano Panizo Galence, Jefe del grupo de Investigación Tecnológica de la Jefatura Superior de Policía de Castilla y León; y el código penal en aquellos artículos referentes a estos delitos.

\section{Metodología: investigación exploratoria-descriptiva}

La investigación que se ha llevado a cabo en este estudio es de carácter exploratorio, pues ofrece un primer acercamiento a un problema social del que hay escasa literatura científica como es al ciberacoso. Tratando de aportar datos científicos que expliquen este comportamiento abyecto. Los resultados derivados de la investigación documental realizada ofrecen un panorama bibliográfico exhaustivo de las teorías vertidas por autoras y autores que han profundizado en este tema. 
Asimismo es una investigación descriptiva que como señala Danhke (1989) "los estudios descriptivos buscan especificar las propiedades, las características y los perfiles importantes de personas, grupos, comunidades o cualquier otro fenómeno que se someta a un análisis". Es en este contexto, los conceptos y definiciones sobre las distintas formas de acoso en la red, y el marco legal que regula las posibles sanciones, se convierten también en los objetivos de la presente investigación.

No obstante, cabe añadir que esta investigación es la antesala de un estudio que presenta los resultados empíricos a partir de la encuesta realizada con jóvenes universitarios, de ambos sexos, sobre su percepción y experiencia a cerca del ciberacoso.

\section{Marco teórico}

\subsection{Concepto de acoso}

Durante los últimos años, son muchos los estudios realizados por parte de educadores, psicólogos, pedagogos y criminólogos, entre otros, sobre el acoso, definido por Olweus (1998) como aquel maltrato y violencia mental o física, de un individuo o un grupo dirigida a otro individuo que no es capaz de defenderse. Según el diccionario de la Real Academia de la Lengua, en su última versión, el concepto "acoso" hace referencia a la acción de "perseguir, sin darle tregua ni reposo, a un animal o a una persona", así como también al acto de "apremiar de forma insistente a alguien con molestias o requerimientos". De estas acepciones podemos considerar el acoso como una conducta de naturaleza ofensiva y perturbadora en la que la persona acosada experimenta sentimientos de angustia y malestar.

Para que una conducta sea considerada como acoso debe comportar un desequilibrio de poder entre las personas involucradas, es decir, entre acosador y acosada/o. Además, estos comportamientos deben repetirse a lo largo del tiempo, llegando a desencadenar graves consecuencias en la persona acosada, tanto físicas como psicológicas (Standler, 2002).Por lo tanto, las dos características principales a destacar a la hora de juzgar una conducta como acoso son:

- Repetición de las conductas llevadas a cabo por el acosador que deben haber sido llevadas a cabo más de una vez o pueden ser susceptibles de ocurrir más veces.

-Desequilibrio que provoca la persona acusadora en el uso del poder (físico, psicológico, social, etc.) para ejercer un control o perpetrar una serie de conductas perjudiciales a la persona acosada (Rovira, 2019).

Las TIC han promovido, sin proponérselo, una nueva forma de intimidación y acoso entre adolescentes conocido como ciberbullying y definida como la utilización de las nuevas tecnologías de la información y de la comunicación tales como Internet (correo electrónico, mensajería instantánea o "chat", páginas web o blogs), el teléfono móvil y los vídeo juegos online principalmente para ejercer acoso psicológico entre iguales (Garaigordobil, 2011). Las redes sociales son terreno propicio para el abuso, la extorsión, el engaño y las conductas violentas. El anonimato, la inmediatez, la viralización son atributos de los entornos digitales, que en manos de la persona agresora, pueden convertirse en estrategias trágicas. Hoy, en un contexto donde la tecnología permite una fácil reproducción y redistribución del contenido ofensivo, es casi seguro que los actos se pueden llegar a repetir con suma facilidad. 
Como recoge el "Estudio sobre la privacidad de los datos personales y la seguridad de la información en las redes sociales online" publicado por el Observatorio de la Seguridad de la Información de INTECO en febrero de 2009, la mayoría de los usuarios de redes sociales, 7 de cada 10, son internautas menores de 35 años: un $36,5 \%$ entre 15 y 24 años y un $32,5 \%$ entre 25 y 34 años.

Más aún, según las últimas cifras del Instituto Nacional de Estadística, 1 de cada 3 jóvenes en España usa redes sociales; en concreto, el porcentaje de usuarios de redes sociales sobre el total de la población española entre 15 y 24 años es el 29\%. De hecho, estudios nacionales e internacionales consideran a este grupo como los usuarios mayoritarios, según el informe de INTECO de 2012.

El término "ciberacoso", a veces denominado "acoso en línea", "acoso electrónico" o "crueldad social en línea" (Kowalski et al., 2012)1, como todas sus variantes, se refiere a todos los actos de lenguaje producidos por individuos o grupos que utilizan tecnologías digitales, que se publican masiva o repetidamente en canales de comunicación públicos o privados, y cuyo propósito es dañar la psicología o el capital social de una tercera persona.

El ciberacoso no es un fenómeno completamente nuevo que hubiera surgido junto con el acoso tradicional. Más bien, es un subconjunto de actos de intimidación cuya particularidad es involucrar el uso de tecnologías y medios digitales. De hecho, como lo muestra la encuesta de Hinduja y Patchin (2010), el 65\% de los adolescentes que afirman haber sido acosados cibernéticamente también informan ser víctimas de la intimidación tradicional. Del mismo modo, el $77 \%$ de los jóvenes que admiten el ciberacoso también informan haber cometido el acoso tradicional. La investigación de Juvoven y Gross (2008) muestra el mismo fenómeno.

\subsection{Ciberbullying}

El informe de Save the Children publicado en el 2019 destacaba que el acoso en las redes sociales a los menores supera ya al tradicional, ese que se desarrolla cara a cara en el centro escolar y que se extiende posteriormente a la calle. Casi 530.000 jóvenes de entre 18 y 20 años reconoce haber sufrido este tipo de violencia cuando era menor de edad a través de las redes, lo que se conoce habitualmente como ciberbullying, que no es otra cosa que ser hostigados, intimidados y excluidos a través de mensajes, imágenes o vídeos, que pretenden dañar, insultar, humillar o difamar. Los afectados sitúan los 8 y 9 años la edad en la que empezaron a ser acosados (Save the Children, 2019).

Para Olweus (1983) el término "acoso" hace referencia a un comportamiento antisocial con tres componentes esenciales: 1) agresión intencional, 2) repetición y 3) un desequilibrio de poder entre el acosador y su víctima. Como veremos más adelante, estos tres componentes a veces están presentes o están ausentes de las representaciones académicas y sociales del ciberacoso.

Asimismo, es necesario trascender el modelo de variables dicotómicas, tales como agresor-victimas, las cuales resultan problemáticas para entender la naturaleza sistémica de las relaciones entre los grupos que son afectados por las distintas formas de acoso; también es necesario adelantar estudios que superen miradas estereotipadas de género que tienden a 
identificar el cyberbullying con alguno de los géneros con una perspectiva simplificadora del problema (Campbell, 2005).

Dado que en la actualidad se constata una prevalencia significativa del cyberbullying y distintas formas de maltrato entre pares y violencia escolar, resulta indispensable conocer con mayor profundidad las causas y consecuencias de comportamientos e interacciones poco explorados, tanto desde el punto de vista de los mismos actores que sufren estos maltratos como desde actores sociales que observan dichos fenómenos con pasividad y sin ninguna intención de intervenir o mediar en dichas situaciones

En un metaanálisis de la literatura científica sobre el ciberacoso, Tokunaga (2010) enumeró nueve definiciones diferentes del ciberacoso utilizadas por los investigadores:

1. El uso de tecnologías de información y comunicación por parte de un individuo o grupo para cometer actos deliberados, repetidos y hostiles para lastimar intencionalmente a otros (Besley, 2009);

2. Amenazas u otros actos ofensivos (excluyendo solicitud sexual) enviados en línea a un joven publicados en línea para que otros jóvenes los vean (Finkelhor et al., 2000)

3. Uso de Internet u otros dispositivos de comunicación digital para insultar o amenazar a alguien (Juvoven y Gross, 2008);

4. Intimidación a través de herramientas de comunicación electrónica como correo electrónico, teléfono celular o PDA ( $\mathrm{Li}, 2008)$;

5. Daños infligidos intencionalmente y repetidamente a través de mensajes de texto (Patchin e Hinduja, 2006);

6. Agresión que se produce a través de dispositivos tecnológicos modernos y, más específicamente, teléfonos móviles o Internet. (Slonjey Smith, 2007);

7. Un acto agresivo e intencional, llevado a cabo por un grupo o un individuo, utilizando formas electrónicas de contacto, repetidamente o a lo largo del tiempo, contra una víctima que no puede defenderse fácilmente. (Smith et al., 2002);

8. Enviar o publicar textos o imágenes ofensivos o violentos a través de Internet u otros dispositivos de comunicación digital (Willard, 2007);

9. Un acto de agresión declarado e intencional hacia otra persona en línea. (Ybarra y Mitchell, 2004)

Por su parte, Kowalski (en Kowalski et al., 2012), sugieren que el ciberacoso es diferente del acoso tradicional por cuatro razones: 1) se puede hacer de forma anónima; 2) puede ser cometido y sufrido en cualquier momento; 3) puede crear el temor de perder el acceso a Internet para las víctimas (que, por lo tanto, se niegan a denunciar a sus atacantes); y 4) muy a menudo da paso a la inacción de los testigos.

En su estudio de 2012 Patchin e Hinduja proporcionan la siguiente explicación para el trabajo sobre la definición del ciberacoso. Conceptualmente, hay varias cuestiones importantes a considerar cuando se trata de definir el acoso cibernético. Lo más importante es el uso de la tecnología para intimidar a una tercera persona. Esta tecnología puede ser una computadora, un teléfono móvil, una tableta, una cámara digital conectada a Internet u otro dispositivo electrónico. Además, el ciberacoso debe implicar daños a una víctima. La víctima o el blanco del acto debe sufrir efectos negativos (psicológicos, emocionales, sociales, etc.). Por otro lado, 
el ciberacoso implica una repetición de actos. Al igual que la intimidación que tiene lugar en contextos tradicionales (en el patio de la escuela o en los pasillos de la escuela), un incidente aislado generalmente no se considera intimidación.

\subsection{Sextorsión}

El término sextorsión2es una contracción de la palabra sexo y extorsión. Como su nombre indica, se trata del chantaje o amenaza de publicar contenido audiovisual o información personal sexual. Así, se entra en la dimensión online del chantaje que puede durar horas, meses o años, y que pude llevarlo a cabo una persona tanto conocida como desconocida por la víctima (Sabina et al. 2008).En cuanto a sus características, existen cuatro elementos esenciales en la sextorsión, que ayudan a concretar una definición completa (Europol, 2017):

1. Material

El objeto del chantaje es un contenido que suele ser íntimo, explícito o embarazoso, normalmente sexual, y que la víctima desea mantener privado. El contenido puede haber sido compartido por la víctima de forma voluntaria, a través del sexting, o no, incluso mediante engaño (Patchin e Hinduja, 2018).

\section{Amenaza}

Este elemento es determinante para la sextorsión. Se trata del escenario que la víctima quiere evitar (normalmente la difusión del material) y es utilizado por quien chantajea para conseguir su objetivo.

3. Valor

El valor es aquello que se pretende conseguir de la víctima. El objetivo puede ser obtener dinero, más material, o que la víctima haga algo.

4. Internet

Internet será el medio para la extorsión, que se dará a través de redes sociales, páginas webs, chats, servicios de mensajería instantánea, etc.

La sextorsión de muestra la relación entre las diferentes formas de violencia electrónica. El chantaje puede ser provocado por la pareja o expareja a la que se envió el contenido de forma voluntaria (Van Ouytsel et al., 2018); por un compañero o compañera de la escuela que tiene imágenes personales de la víctima y las utiliza; o de una persona adulta con la que la víctima ha contactado de forma previa por internet y con quien guarda una comunicación constante (Wolak, J., y Finkelhor, D., 2016).

\subsection{Violencia online en la pareja o expareja}

Esta violencia se define como el conjunto de comportamientos repetidos que pretenden controlar, menoscabar o causar un daño a la pareja o expareja(Gámez-Guadix et al., 2018). Por lo que es muy probable que quien sufra o provoque violencia en el mundo físico, lo haga también en el virtual (Schnurr et al. ,2013), (Zigis et al.,2013) Las TIC serán el canal para la que la violencia continúe (facilitador) o actuará como "detonante". Un ejemplo claro sería una persona que ve una foto o comentario en internet de su pareja, lo que provoca un sentimiento de celos y desemboca en una agresión física o verbal (Melander, 2010).

Se lleva a cabo mediante el intercambio de mensajes, control de las redes sociales o webs, apropiación de las contraseñas, difusión de secretos o información comprometida, amenazas e insultos (Gámez-Guadix et al., 2018). Se puede vigilar a la pareja controlando su ubicación, 
conversaciones, comentarios online, enviando correos, mensajes o comentarios humillantes, groseros o degradantes, o publicando fotos con la misma intención (Hinduja y Patchin, 2011).

En este caso también se entrelazan otras formas de violencia, como la sextorsión, el ciberacoso o el sexting sin consentimiento. El peligro añadido que caracteriza a este tipo de violencia entre adolescentes se produce cuando se justifica, se resta importancia o se menosprecian las consecuencias de estas conductas; incluso hay ocasiones en las que se confunden como una expresión de amor o afecto(Borrajo et al., 2015). Por ejemplo, que los celos son una expresión de amor o que estar con una persona otorga el derecho de controlarla (Gámez et al., 2018) Así, esta violencia es de extrema importancia en esta etapa de la vida, donde se comienzan las primeras relaciones afectivas sexuales, y se sientan las bases para las futuras relaciones en la edad adulta. Por ello, niñas, niños y adolescentes necesitan aprender conductas sanas, libres de las desigualdades y los roles de género e identificar los comportamientos que son violentos, evitando normalizarlos.

Aprender desde edades tempranas unos modelos de relación sanos y desde el respeto mutuo es una forma de prevención clave contra la violencia en la pareja, especialmente contra la violencia de género.

\subsection{Online grooming}

Este fenómeno relativamente nuevo, el online grooming, hace referencia al engaño y acoso sexual que sufren menores en la red por parte de adultos en $A B C, 28 / 09 / 2019$ ).

El online grooming (acoso y abuso sexual online) es un delito por el cual una persona adulta contacta electrónicamente con un niño, niña, adolescente o joven ganándose poco a poco su confianza con el propósito de involucrarle en una actividad sexual. Esta puede ir desde hablar de sexo y obtener material del mismo tipo, hasta mantener un encuentro sexual (Craven et al., 2006).

Si bien existen múltiples formas de ciberembaucamiento, y cada caso es diferente, han podido identificar patrones de conducta que pueden ayudar a prevenir y detectar un caso de online grooming. Estas conductas pueden no seguir una línea temporal ordenada, sino superponerse entre sí (Black et al., 2015).

Las fases del online grooming o ciberembaucamiento (O'Connell, 2003):

1. Vínculo de confianza.

La persona agresora contacta con la víctima y establece el vínculo de confianza, a menudo mediante sobornos o engaños (Gámez-Guadix et al., 2018). La unión puede llegar a ser tan fuerte que a la víctima le resulte imposible romper el vínculo porque lo considera realmente importante. Para ello, quien abusa puede:

- Fingir otra identidad, como una persona de edad cercana o similar a la de la víctima.

- Hacerle regalos

- Ofrecer una amistad pretendiendo comprender sus problemas y empatizando a un nivel profundo. En ocasiones, puede aprovechar una necesidad afectiva del niño o niña en su entorno offline.

- Recabar información personal de la víctima para relacionarse con ella, embaucarla y 
realizar posteriormente un chantaje.

2. Aislamiento de la víctima.

El aislamiento de la víctima persigue arrancar su red de apoyo natural (familiares, amistades, docentes, etc.) dejándola desprotegida.

De esta manera:

- Puede insistir en la necesidad de que su relación sea secreta, privada y confidencial, incluidas las conversaciones.

- Convence a la niña o niño de que no debe compartir con nadie más lo que comparten entre sí.

3. Valoración del riesgo.

El perpetrador o perpetradora quiere asegurarse de esta privacidad. Es crucial que la víctima mantenga en secreto la relación, por lo que podrá:

- Preguntar si alguien más conoce la situación.

- Averiguar quién tiene acceso al ordenador o dispositivo que utilicen para comunicarse.

- Preguntar si alguien controla o vigila el uso que hace de internet, redes y chats.

- Adaptar su lenguaje y comportamiento a las características la víctima(Wolak et al., 2010).

4. Petición sexual

Es el objetivo principal del online grooming. Esta solicitud se traduce en una proposición para que la víctima envíe material sexual, tome parte o relate fantasías sexuales o incluso sugerir un encuentro físico. En esta fase, las técnicas suelen ser la manipulación, las amenazas, la coerción o el chantaje. Así, puede incitar a la víctima a enviarle fotografías con sugerencias del estilo: "Tal vez puedas tomar fotografías tuyas tocándote a ti misma".

- En las conversaciones se recrean fantasías sexuales y pide a la víctima que le diga lo que quiere.

- Convencer a la víctima para un encuentro en persona: "Tal vez podríamos encontrarnos algún día y podría mostrarte cuánto te quiero".

- Manipular con frases como: "Hazlo, demuéstrame que me quieres, no me falles".

- Amenazar o chantajear con difundir información o material que hayan compartido. (Mitchell et al.,2001).

\section{La ley ante el ciberacoso}

Panizo Galence describe las importantes ventajas para los delincuentes puesto que Internet les hadado la posibilidad de perpetrar acciones criminales a cientos de kilómetros, pudiendo utilizar identidades supuestas, técnicas de navegación anónima y todo ello con el fin de dificultar su identificación.

Internet también ha traído la aparición de nuevas conductas ilícitas que, por su gravedad, merecen un reproche penal y que no estaban recogidas como tales en nuestra legislación: intrusiones ilegales en sistemas informáticos, daños informáticos, ataques de denegación de servicio, estafas utilizando las nuevas tecnologías (phishing, pharming, clonación tarjetas bancarias...), distribución de pornografía infantil, ciberacoso, etc. (2011)

Panizo Galence trata esta situación como un reto para las autoridades nacionales de cualquier país. Apuntando una serie de cuestiones que las autoridades deben de abordar. La primera cuestión implica adaptar las legislaciones nacionales y adaptarlas a estos nuevos ilícitos pe- 
nales. En España, la Ley Orgánica 5/2010, de 22 de junio, de reforma del Código Penal tipificó, entre otras figuras, el llamado childgrooming (Art. 183 bis), el acceso ilegal a sistemas informáticos (Art. 197.3), las estafas utilizando las nuevas tecnologías (Art. 248.2) y daños informáticos en sus distintas vertientes (Art. 264).También apunta a la necesidad de crear unidades policiales especializadas en la investigación de delitos tecnológicos con una formación adecuada, especializada y continua (2011).

El uso de las nuevas tecnologías, más concretamente los smartphones han ayudado que sea común y habitual hacer una foto, a uno mismo o a otra persona, y compartirla en redes. El hecho es tan habitual que con frecuencia los autores de estas conductas no son conscientes de ello. Grabar y compartir videos en Internet ofensivos para otros adolescentes, hacer comentarios insultantes en foros, chats o muros de las redes sociales, alojar en páginas web o enviar a través deservicios de mensajería fotos o videos en situaciones comprometidas o embarazosas, hacer llamadas intimidatorias, enviar correos electrónicos o SMS ofensivos.

Se trata de prácticas de carácter delictivo recogidas en el ordenamiento jurídico. El Artículo 18 de la Constitución Española se centra en una serie de derechos que tienen que ver con la integridad del individuo. En este artículo se recoge: a) el derecho a la intimidad frente injerencias ajenas, b) a la dignidad persona cuando se es vejado, insultado, amenazado o excluido, c) el derecho al honor pudiendo proteger la dignidad como la reputación de una persona en la sociedad y d) el derecho a la propia imagen, que otorga el derecho a controlar la difusión del aspecto más externo, el de la figura humana.

La expansión de las nuevas tecnologías de la información y la comunicación están contribuyendo a la vulneración de todos estos derechos. La publicación a través de Internet de comentarios o informaciones sobre personas con insultos, calumnias, injurias o acusándolas de hechos inciertos o que menoscaban su imagen pública son una clara vulneración del derecho al honor. Del mismo modo, publicar fotos o vídeos, en cualquier red social, de otras personas, sin su consentimiento, en actitudes o situaciones comprometedoras, incómodas o que proyecten una imagen negativa, el uso de datos personales y/o su difusión, la vulneración del secreto de las comunicaciones, las amenazas vertidas a través de distintos soportes tecnológicos son ejemplos de vulneraciones de los derechos a la intimidad, la dignidad personal, el honor o la imagen personal.

Por ello es importante conocer que muchas de las acciones que las personas llevan a cabo en el mundo digital, incluso cuando no las realizan con el ánimo claro de hacer daño a otras personas, constituyen conductas consideradas como delitos en el Código Penal.

\subsection{El código penal}

El código penal español especifica una serie de penas para los delitos relacionados con la vulneración de los derechos del Artículo 18 de la Constitución Española.

En el Artículo 197 se especifica que: 1) aquellos delitos relacionados con la vulneración de la intimidad de otro, que sin su consentimiento, se apodere de documentos tanto en formato físico como digital por cualquier medio interceptación, se prevén penas de prisión de uno a cuatro años y multa de doce a veinticuatro meses; 2) esas mismas penas se impondrán a aquellos 
que modifiquen datos en cualquier formato o soporte en perjuicio de terceros; así como el acceso ilegal a estos datos; 3) por difundir, revelar o ceder datos a terceros, correspondientes a los dos puntos anteriores del articulado, se impone una pena de dos a cinco años. Asimismo, también se castiga al que conociendo el origen ilícito la distribuye, aun sin haber tomado parte, con penas de prisión de uno a tres años y multa de doce a veinticuatro meses; 4) Los hechos descritos en los apartados 1 y 2 de este artículo serán castigados con una pena de prisión de tres a cinco años cuando: sean las personas encargadas o responsables de la protección de esos datos o se utilicen de manera no autorizada; 5) Si los hechos descritos en los apartados anteriores afectan a datos de carácter personal que revelen cuestiones como origen racial, vida sexual, minoría de edad, salud, etc. se aplicarán las penas que aparecen en los primeros puntos del articulado;6) si el delito se ha realizado con ánimo de lucho se imponen las penas respectivamente previstas en los apartados 1 al 4. Si además afectan a datos de los mencionados en el apartado anterior, la pena a imponer será la de prisión de cuatro a siete años; 7) difundir imágenes de terceros obtenidas en lugares cerrados o alejados de miradas ajenas cuando la divulgación menoscabe gravemente la intimidad personal de esa persona, tiene una pena de prisión de tres meses a un año o multa de seis a doce meses. Siendo un agravante el haber sido cónyuge o haber compartido una relación aun sin convivencia.

El Artículo 197 bis. amplia con un par de puntos las condenas que vulnera el Artículo 18 de la Constitución Española. Concretamente con 1) la vulneración de medidas de seguridad destinadas para impedir la intrusión en sistema de información se castiga con pena de prisión de seis meses a dos años. 2) Está penado con prisión, de tres meses a dos años o multa de tres a doce meses, la interceptación de transmisiones no públicas de datos informáticos.

El Artículo 197 ter. Especifica una pena de prisión de seis meses a dos años, o multa de tres a dieciocho meses, al que, de cualquier modo, facilite a terceros, la comisión de alguno de los delitos a que se refieren los apartados 1 y 2 del artículo 197 o el artículo 197 bis. En este apartado podemos incluir cualquier tipo de software malicioso, cualquier contraseña o código de acceso a un sistema privado de información. Si bien el Artículo 197 viene a penar aquellos derechos plasmados en el Artículo 18 de la Constitución, la ampliación viene a proteger los grandes sistemas informáticos en el ámbito privado, mientras que el último punto se refiere a la labor de intermediario en la comisión del delito.

En el Artículo 208 del código penal se especifica cuando una injuria es delito. Por ejemplo aquellas que, por su naturaleza, efectos y circunstancias, sean tenidas en el concepto público por graves, sin perjuicio de lo dispuesto en el apartado 4 del artículo 173.Las injurias que consistan en la imputación de hechos no se considerarán graves, salvo cuando se hayan llevado a cabo con conocimiento de su falsedad. En el Artículo 209 se especifica que las injurias graves hechas con publicidad se castigarán con la pena de multa de seis a catorce meses y, en otro caso, con la de tres a siete meses. Ambos artículos responden a la práctica más esencial del acoso: la injuria. Que como se ha podido comprobar aparece de manera transversal en la mayoría de las prácticas.

Impedir el acceso a datos personales o destruir un sistema informático de cualquiera de las maneras haciendo este irrecuperable será castigado, con la pena de prisión de seis meses a tres años según el Artículo 264. Penando las prácticas de cibercontrol que sufren muchas mujeres por parte de sus parejas. 


\section{Conclusiones}

La investigación es el primer paso hacia políticas y programas efectivos en la lucha contra la violencia contra la infancia, adolescencia y, cualquier persona víctima del ciberacoso. Sin embargo, la información de la que se dispone todavía es insuficiente, por eso debemos seguir estudiando este fenómeno y considerando sus diferentes aspectos.

La sensibilización de la sociedad ante la violencia con las tecnologías comienza con la información y, posteriormente, la comprensión. Hay que dejar de lado los prejuicios y miedos ante el uso de las TIC, pero también hay que conocer el uso torticero que se puede llegar a dar, los contextos proclives, y los perfiles de las personas más vulnerables.

En este estudio se ha comprobado que una parte de las acciones de violencia acosadora están recogidas y penalizadas por la ley, pero aún queda mucho margen de maniobra para ampliar la normativa que dé cobertura a todas las acciones y contextos que se suscitan por toda la Red. La casuística es tan diversa que se pone de manifiesto la dificultad de perseguir y denunciar a su debido tiempo todas realidades posibles.

Tomando como referencia las situaciones en las que se dan las diversas formas de acoso y ciberacoso, se proponen las siguientes acciones:

- Profundizar en el estudio sobre los diversos usos que los colectivos más vulnerables hacen de internet y el impacto que tienen en su conducta.

- Estudiar los comportamientos y características de quienes se implican en la violencia online.

- Unificar las definiciones existentes para poder comparar los resultados de diversos estudios con mayor facilidad.

- Desarrollar una línea de investigación que evalúe los efectos y la eficacia de diversas acciones destinadas a prevenir, detectar y actuar contra la violencia online.

- Revisar las producciones comerciales y/o artísticas que refuerzan falsas creencias que justifican o fomentan la violencia.

- Reflexionar sobre la hipersexualización de niñas y niños (especialmente de las primeras), en medios de comunicación, publicaciones, etc. En este último apartado es conveniente tener en cuenta los datos de la investigación de Víctor Grande-López, según los cuales "a medida que las niñas van haciéndose adolescentes surge una mayor preocupación por su imagen de un $39 \%$ a un $78 \%$. Y los medios no solo influyen sino que un $25 \%$ de niñas de 7 a 10 años se siente presionadas por ellos" (2019).

\section{Notas}

(1) Más raramente "usos maliciosos de tecnologías" y/o "comportamiento antisocial en línea".

(2) También denominado como "porno de venganza".

\section{Bibliografía}

ABC (28/09/2019). Grooming, el peligro de las redes sociales para tus hijos. ABC.https://www. abc.es/familia/padres-hijos/abci-grooming-peligro-redes-sociales-para-hijos-201909280137_ noticia.html [Consultado el 20/02/2020]. 
Bernal, C., (2006). Metodología de la investigación. Tercera edición. Pearson educación: Colombia.

Besley, B. (2009). Cyberbullying. http://www.cyberbullying.org/ [Consultado el 10 de abril de 2020].

Black, P. J., Wollis, M., Woodworth, M., y Hancock, J. T. (2015). A linguistic analysis of grooming strategies of online child sex offenders: Implications for our understanding of predatory sexual behavior in an increasingly computer-mediatedworld. Child Abuse \& Neglect, 44, pp. 140-149.

Bonilla Castro, E. y Rodríguez S. P. (2005). Más allá del dilema de los métodos: La investigación en ciencias sociales. Bogotá: Grupo Editorial Norma.

Borrajo, E., Gámez Guadix, M., y Calvete, E. (2015). Justification beliefs of violence, myths about love and cyberdating abuse. Psicothema. 27(4), pp. 327-333.

Campbell, M. (2005). Cyberbullying: An old problema in a new guise? Australian Journal of Guidance and Couselling, 15(1), pp. 68-76. doi:10.1375/ajgc.15.1.68

Craven, S., Brown, S., y Gilchrist, E. (2006). Sexual grooming of children: Review of literature and theoretical considerations. Journal of Sexual Aggression, 12(3), pp. 287-299.

Dankhe, G. L. (1989) Investigación y Comunicación en C. Fernández-Collado y G. L. Dankhe (comps.), La Comunicación Humana: Ciencia Social, Ed. McGraw Hill, México.

Echeburúa, E. y de Corral, P. (2010). Adicción a las nuevas tecnologías y a las redes sociales en jóvenes: un Nuevo reto. Adicciones. n 22(2), abril 2010, pp. 91-95.

Eddy Ives, L.S., (2012). Ciberacoso y grooming. En Familia (Asociación Española de Pediatría). http://enfamilia.aeped.es/vida-sana/ciberacoso-grooming [Consultado el 10 de abril de 2020].

Europol (2017). Online sexual coercion and extortion as a form of Crime affecting children. Law enforcement perspective. www.europol.europa.eu. [Consultado el 20/03/2020].

Finkelhor, D , Mitchell, K., y Wolak, J., (2000). Online "Predators" and Their Victims: Myths, Realities, and Implications for Prevention and Treatment. American Psychologist 63(2), pp. 111-28.

Gámez-Guadix, M., Almendros, C., Calvete, E., y De Santisteban, P. (2018). Persuasion strategies and sexual solicitations and interactions in online sexual grooming of adolescents: Modeling direct and indirect pathways. Journal of Adolescence, 63, pp. 11-18.

Gámez-Guadix, M., Borrajo, E. y Calvete, E. (2018). Abuso, control y violencia en la pareja a través de internet y los smartphones: características, evaluación y prevención. Papeles del Psicólogo, 39(3), pp. 218-227.

Garaigordobil, M. (2011). Prevalencia y consecuencias del cyberbullying: una revisión. Interna- 
tional Journal of Psychology and Psychological Therapy 2011, 11, 2, pp. 233-254.

Garmendia, M., Garitaonandia, C., Martínez, G. y Casado, MA. (2011). Riesgos y seguridad en Internet: los menores españoles en el contexto europeo. EU kids Online. Bilbao: Universidad del País Vasco.

Gladden, R., Vivolo-Kantor, A., Hamburger, M., y Lumpkin, C., (2014). Bullying surveillance among youths: Uniform definitions for public health and recommended data elements. https://www.cdc.gov/violenceprevention/pdf/bullying-definitions-final-a.pdf [Consultado el 30/12/2019]

Grande-López, V (2019). La hipersexualización femenina en los medios de comunicación como escaparate de belleza y éxito. Communication Papers, Vol.8 - No16, pp. 21-32. http://dx.doi.org/10.33115/udg_bib/cp.v8i16.22356

Hinduja, S. y Patchin, J. (2010). Bullying, Cyberbullying, and Suicide. Archives of suicide research: oficial journal of the International Academy for Suicide Research. 14. pp. 206-21.

INTECO (Instituto Nacional de Tecnologías de la Comunicación) (02/2009): Estudio sobre la privacidad de los datos personales y la seguridad de la información en las redes sociales online, Observatorio de la Seguridad de la Informaciónhttps://www.csirtcv.gva.es/sites/all/files/ downloads/estudio_intecoaepd_privacidad_redes_sociales.pdf [Consultado el 30/12/2019]

INTECO (2013). Guía SOS contra el grooming. Padres y educadores. http://www.adolescenciasema.org/usuario/documentos/sos_grooming.pdf [Consultado el 10 de abril de 2020].

INTECO (2011) Guía sobre adolescencia y sexting: qué es y cómo prevenirlo. https://www. sexting.es/wp-content/uploads/guia-adolescentes-y-sexting-que-es-y-como-prevenirlo-INTECO-PANTALLASAMIGAS.pdf [Consultado el 10/04/2020].

INTECO (2012) Guía de actuación contra el ciberacoso para padres y educadores. Injuve: http://www.injuve.es/sites/default/files/Gu\%C3\%ADa\%20de\%20actuaci\%C3\%B3n\%20contra\%20el\%20ciberacoso.pdf. [Consultado el 10 de abril de 2020].

INTECO (2012) Guía legal sobre ciberbullying y grooming. https://www.educacion.navarra.es/ documents/57308/57740/ciberbullyng.pdf/1c169fb5-b8ab-478f-b7f4-7e3d22adab14 [Consultado el 10/04/2020].

Kowalski, R. M. y Limber, S. P. (2012).Traditional bullying as a potential warning sign of cyberbullying. https://doi.org/10.1177/0143034312445244. [Consultado el 17 enero 2020].

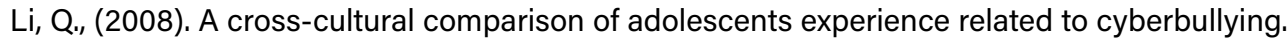
Educational Research, 50(3), pp. 223-234.

Melander, L. A. (2010). College students' perceptions of intímate partner cyberharassment. Cyberpsychology, Behavior, and Social Networking, 13, pp. 263-268. 
Mitchell, K. J., Finkelhor, D., y Wolak, J. (2001). Risk factors for and impact of online sexual solicitation of youth. Journal of the American Medical Association, 285(23), pp. 3011-3014.

O'Connell, R. (2003). A typology of child cybersexploitation and online grooming practices. Cyberspace Research Unit. http://image.guardian.co.uk/sysfiles/Society/documents/2003/07/17/Groomingreport.pdf [Consultado el 17 enero 2020]

Olweus, D. (1983). Low school achievement and aggressive behaviour in adolescent boys. Human. Development and Interactional Perspective. Nueva York: Academic Press, pp. 353-365

Olweus, D., (1998), Conductas de acoso y amenazas entre escolares. Morata, Madrid.

Panizo Galence, V (2011). El ciber-acoso con intención sexual y el child-grooming. Quadernos de criminología: revista de criminología y ciencias forenses, 15. pp. 22-33

Patchin, J. W. e Hinduja, S. (2006). Bullies move beyond the schoolyard: A preliminary look at cyberbullying. Youth Violence and Juvenile Justice, 4(2), pp. 148-169.

Patchin, J. W., e Hinduja, S. (2018). Sextortion among adolescents: Results from a national survey of US youth. Sexual Abuse, pp. 1-25.

Patchin, J. W., e Hinduja, S. (2012). Cyberbullying: An update and synthesis of the research. En J. W. Patchin y S. Hinduja (Eds.), Cyberbullying prevention and response: Expert perspective. Routledge/Taylor \& Francis Group. Pp. 13-35

Rovira, I. (s.f.). Los 7 tipos de acoso y sus características. Psicología y mente. https://psicologiaymente.com/social/tipos-de-acoso [Consultado el 30/12/2019]

Sabina, C., Wolak, J. y Finkelhor, D. (2008). The nature and dynamics of internet pornography exposure for youth. Cyber Psychology \& Behavior, 11(6), pp. 691-693.

Save the Children(2019). Violencia Viral, análisis de la violencia contra la infancia y la adolescencia en el entorno digital. https://www.savethechildren.es/publicaciones/informe-violencia-viral-y-online-contra-la-infancia-y-la-adolescencia [Consultado el 11/04/2020].

Schnurr, M. P., Mahatmya, D., y Basche, R. A. (2013). The role of dominance, cyberaggression perpetration, and gender on emerging adults' perpetration of intímate partner violence. Psychology of Violence, 1, pp. 70-83.

Slonje, R., y Smith, P. K. (2008).Cyberbullying: Another main type of bullying? Scandinavian Journal of Psychology, 49, pp. 147-154.

Smith, P. K., Cowie, H., Ólafsson, R. F. y Liefooghe, A. P. D. (2002). Definition of Bullying: a comparison of terms used, and age and gender differences, in a fourteen country international comparison. Child Development, 73, pp. 1119-1133. 
Standler, R. B. (2002). ComputerCrime. http://www.rbs2.com/ccrime.htm [Consultado el 30/12/2019]

Tokunaga, R. (2010).Following you Home from School: A Critical review and Synthesis of Research on Cyberbullying Victimization.Computers in Human Behavior 26(3), pp. 277-287

Van Ouytsel, J., Ponnet, K., y Walrave, M. (2018). Cyberdating abuse victimization among secondary school students from a lifestyle-routine activities theory perspective. Journal of Interpersonal Violence, 33(17), pp. 2767-2776.

Willard, N. E. (2007). Cyberbullying and Cyberthreats: Responding to the Challenge of Online Social Aggression, Threats, and Distress: http://csriu.org y http://cyberbully.org [Consultado el 17 enero 2020]

Wolak, J., y Finkelhor, D. (2016). Sextortion: Findings from a survey of 1,631 victims. Manchester, New Hampshire: Crimes against Children Research Center.

Wolak, J., Finkelhor, D., Mitchell, K., e Ybarra, M. (2010). Online "predators" and their victims

Ybarra, M. L., y Mitchell, K. J. (2004). Online aggressor/targets, aggressors, and targets: A comparison of associated youth characteristics. Journal of Child Psychology and Psychiatry, 45(7), pp. 1308-1316.

Zigis, J. M., Dank, M., Yahner, J., y Lachman, P. (2013). The rate of cyberdating abuse among teens and how it relates to other forms of teen dating violence. Journal of Youth and Adolescence, pp. 1-15 


\section{CURRICULUM VITAE}

Miguel A. Pérez-Gómez

Miguel A. Pérez-Gómez es Licenciado y Doctor en Comunicación Audiovisual por la Universidad de Sevilla donde es docente en el Departamento de Comunicación Audiovisual y Publicidad. Pertenece al Grupo de Investigación ADMIRA (SEJ-496: Análisis de Medios, Imágenes y Relatos Audiovisuales en su Historia para el Cambio Social). Sus investigaciones se centran en cultura de participación, el fandom, cultura popular japonesa, el cine fantástico español y el cómic. También ha colaborado en publicaciones como Rock de Lux y la revista online Entrecómics, en la actualidad sigue escribiendo sobre el $9^{\circ}$ arte en su blog El lector bicéfalo.

\section{Carmen Echazarreta Soler}

Profesora de Comunicación de la Universidad de Girona. Doctora en Comunicación por la Universidad de Barcelona (2002) y licenciada en Comunicación (1990), Estudios del Asia oriental (2006) y Prehistoria e Historia antigua. En la actualidad es Vicedecana de la Facultad de Turismo y Comunicación.Ha impartido e imparte docencia en el grado de Publicidad, en el grado de Desarrollo de Videojuegos y en los Masters de Estudios culturales y Comunicación, de Comunicación Política y de Igualdad de Género en la Universidad Autónoma de Barcelona. Es Investigadora principal del grupo de Investigación ARPA -Análisis de la Recepción de las Pantallas audiovisuales- y editora de la revista científica en Comunicación Communication Papers (www.communicationpapers.com).

\section{Meritxell Audebert}

Graduada en Comunicación Audiovisual por la Universitat de Vic y actual estudiante de Publicidad y Relaciones Públicas por la Universitat de Girona. Ha realizado diferentes trabajos de investigación sobre la desigualdad de género, talleres sobre el ciberacoso y trabajos artísticos sobre la plasticidad de los cuerpos ("El cuerpo habla por mí", disponible en https://www.cinemagender.com/las-mariconos).

\section{Cristina Sánchez Miret}

Doctora en Sociología y Directora del Departamento de Empresa de la Universitat de Girona. Miembro de Grupo de trabajo impulsor del Plan estratégico UdG 2030, La Suma d'Intel.ligències. Especializada en la investigación sobre la desigualdad social relacionada con el género, la edad, la clase social y el estilo de vida, y en la participación ciudadana, temas en los que ha colaborado y colabora en varios proyectos de investigación nacionales e internacionales. 